\title{
Phylogenetic Analysis of Bean yellow mosaic virus Isolates from Four Continents: Relationship Between the Seven Groups Found and Their Hosts and Origins
}

\author{
S. J. Wylie, State Agricultural Biotechnology Centre, Murdoch University, Perth, WA 6150, Australia, and Centre for \\ Legumes in Mediterranean Agriculture, University of Western Australia, Perth, WA 6009, Australia; B. A. Coutts, Ag- \\ ricultural Research Western Australia, Locked Bag No. 4, Bentley Delivery Centre, Perth, WA 6983, Australia; \\ M. G. K. Jones, State Agricultural Biotechnology Centre, Murdoch University, Perth, WA 6150, Australia; and \\ R. A. C. Jones, Agricultural Research Western Australia, Locked Bag No. 4, Bentley Delivery Centre, Perth, WA 6983, \\ Australia, State Agricultural Biotechnology Centre, Murdoch University, Perth, WA 6150, Australia, and School of Plant \\ Biology, University of Western Australia, Perth, WA 6009, Australia
}

\begin{abstract}
Wylie, S. J., Coutts, B. A., Jones, M. G. K., and Jones, R. A. C. 2008. Phylogenetic analysis of Bean yellow mosaic virus isolates from four continents: Relationship between the seven groups found and their hosts and origins. Plant Dis. 92:1596-1603.

Genetic diversity of Bean yellow mosaic virus (BYMV) was studied by comparing sequences from the coat protein (CP) and genome-linked viral protein $(\mathrm{VPg})$ genes of isolates from four continents. CP sequences compared were those of 17 new isolates and 47 others already on the database, while the VPg sequences used were from four new isolates and 10 from the database. Phylogenetic analysis of the $\mathrm{CP}$ sequences revealed seven distinct groups, six polytypic and one monotypic. The largest and most genetically diverse polytypic group, which had intragroup diversity of 0.061 nucleotide substitutions per site, contained isolates from natural infections in eight host species. These original isolation hosts included both wild (four) and domesticated (four) species and were from monocotyledonous and dicotyledonous plant families, indicating a generalized natural host range strategy. Only one of the other five polytypic groups spanned both monocotyledons and dicotyledons, and all contained isolates from fewer species (one to four), all of which were domesticated and had lower intragroup diversity ( 0.019 to 0.045 nucleotide substitutions per site), indicating host specialization. Phylogenetic analysis of the fewer VPg sequences revealed three polytypic and two monotypic groupings. These groups also correlated with original natural isolation hosts, but the branch topologies were sometimes incongruous with those formed by CPs. Also, intragroup diversity was generally higher for VPgs than for CPs. A plausible explanation for the groups found when the 64 different $\mathrm{CP}$ sequences were compared is that the generalized group represents the original ancestral type from which the specialist host groups evolved in response to domestication of plants after the advent of agriculture. Data on the geographical origins of the isolates within each group did not reveal whether the specialized groups might have coevolved with their principal natural hosts where these were first domesticated, but this seems plausible.
\end{abstract}

Additional keywords: evolution, phylogeography, Potyviridae

Bean yellow mosaic virus (BYMV) is a member of the genus Potyvirus (family Potyviridae), which constitutes the largest and economically most important group of plant viruses (41). BYMV occurs worldwide and infects species within several monocotyledonous and dicotyledonous plant families. Before nucleotide (nt) sequencing became available, host range, symptomatology, serology, peptide profil-

Corresponding author: R. A. C. Jones

E-mail: rjones@agric.wa.gov.au

Accepted for publication 7 August 2008.

doi:10.1094/PDIS-92-12-1596

(C) 2008 The American Phytopathological Society ing, and nucleic acid hybridization techniques were used to elucidate relationships between BYMV-like potyviruses. Based on the peptide profiles of the coat protein (CP), Randles et al. (37) proposed a BYMV subgroup within the potyviruses comprising BYMV, Pea mosaic virus (PMV), and Sweet pea mosaic virus (SPMV). Later, Clover yellow vein virus (ClYVV) (2,49), White lupin mosaic virus (WLMV) (19), and Sesbania virus (SeV) (15) were proposed as additional BYMV subgroup members. The first complete $\mathrm{CP}$ nucleotide sequence for BYMV was published in 1989 (18). In 1993, McKern et al. (30) showed that the differences between the CPs of PMV and WLMV could be accounted for by normal within-species variation, so both were reclassified as strains of BYMV, but this was not the case with CIYVV, which was still considered a distinct virus. The status of SPMV and $\mathrm{SeV}$ remain unclarified. In 1992, Hampton et al. (19) predicted that the BYMV subgroup would contain many further members from different agroecosystems. In 2005, Adams et al. (1) compared all available potyvirus $\mathrm{CP}$ sequences, employing molecular criteria to distinguish among different species. BYMV and ClYVV were confirmed to be related but distinct viruses. However, the existence of a distinct BYMV subgroup was not supported.

Many strains of BYMV have been reported, distinguished by pathogenicity, serological properties, or more recently, molecular diversity $(5,11,23,39,49,50,51)$. For example, based on host pathogenicity, three BYMV strains were described in Japan by Inouye (23): 'B' from Vicia faba (broad bean), 'P' from Pisum sativum (pea), and ' $\mathrm{O}$ ' from Phaseolus vulgaris (common bean). Later studies using RNA/ cDNA hybridization analysis of whole genomes, or differential host responses and serology, indicated four genetically distinct groups that corresponded with the 'B', 'P', and ' $\mathrm{O}$ ' strains of Inouye (23) and a new one represented by isolates from Gladiolus hybrida (Gladiolus) $(39,51)$. A later analysis of the CP sequences of 24 isolates also indicated the existence of four distinct BYMV groups (5).

In addition to virion packaging, the CPs of potyviruses are involved in virus/vector interactions, spread of infectious viral RNA from cell to cell, long-distance movement within the plant (10), and the recruitment of host-encoded susceptibility factors (22). The genome-linked viral protein $(\mathrm{VPg})$, either alone or in concert with other viral proteins, has multiple functions: translation of the viral polyprotein through interaction with the cap-binding protein (eIF4E) (3), cell-to-cell trafficking (13), and host range determination (36). However, unlike the $\mathrm{CP}$, it is rarely used to distinguish potyviruses in phylogenetic studies (1). 
Table 1. Isolates with coat protein sequences used

\begin{tabular}{|c|c|c|c|c|c|c|}
\hline Isolate & Geographical origin ${ }^{a}$ & Original host species & Host family & Status $^{b}$ & Accession no. & Original isolate ref. \\
\hline \multicolumn{7}{|l|}{ Australian } \\
\hline BadgB-1 & Badgingarra, W. Australia & Kennedia prostrata ${ }^{\mathrm{c}}$ & Fabaceae & Native & DQ901433 & 52 \\
\hline Diurus & ACT, Australia & Diuris maculata & Orchidaceae & Native & AF185962 & 14 \\
\hline FBMj & Manjimup, W. Australia & Vicia faba & Fabaceae & Domesticated & EU082112 & 7 \\
\hline FBD1 & Dongara, W. Australia & V. faba & Fabaceae & Domesticated & EU082117 & 7 \\
\hline FBD2 & Dongara, W. Australia & V.faba & Fabaceae & Domesticated & EU082128 & 7 \\
\hline FBD3 & Dongara, W. Australia & V. faba & Fabaceae & Domesticated & EU082113 & 7 \\
\hline FBI-1 & Irwin, W. Australia & V.faba & Fabaceae & Domesticated & EU082116 & 7 \\
\hline FBI-2 & Irwin, W. Australia & V. faba & Fabaceae & Domesticated & EU082114 & 7 \\
\hline FBI-3 & Irwin, W. Australia & $V \cdot f a b a$ & Fabaceae & Domesticated & EU082115 & 7 \\
\hline $\mathrm{KP}$ & The Lakes, W. Australia & K. prostrata ${ }^{\mathrm{c}}$ & Fabaceae & Native & DQ901432 & 31 \\
\hline LCbk-NN & Cranbrook, W. Australia & Lupinus angustifolius & Fabaceae & Domesticated & AF192783 & 7 \\
\hline LDw-NN & Dowerin, W. Australia & L. angustifolius & Fabaceae & Domesticated & EU082118 & 7 \\
\hline LKoj1-NN & Kojonup, W. Australia & L. angustifolius & Fabaceae & Domesticated & AF19282 & 7 \\
\hline LNgn-NN & Narrogin, W. Australia & L. angustifolius & Fabaceae & Domesticated & EU082121 & 7 \\
\hline LutKP-1 & Kirup, W. Australia & Lupinus luteus & Fabaceae & Naturalized & AF192781 & 6 \\
\hline LutKP-2 & Kirup, W. Australia & L. luteus & Fabaceae & Naturalized & EU082122 & 6 \\
\hline MI & South Perth, W. Australia & Melilotus indica & Fabaceae & Wild & X81124 & 24 \\
\hline MI-NAT & South Perth, W. Australia & M. indica & Fabaceae & Wild & AF434661 & 53 \\
\hline MUB-1 & Murdoch, W. Australia & $K$. prostrata $^{\mathrm{c}}$ & Fabaceae & Native & DQ901431 & 52 \\
\hline I & Vic, Australia & Pisum sativum & Fabaceae & Domesticated & S71232 & 46 \\
\hline Pterostylis & Australia & Pterostylis curta ${ }^{\mathrm{c}}$ & Orchidaceae & Native & AF185960 & 14 \\
\hline PvB-1 & Mt. Pleasant, W. Australia & Phaseolus vulgaris & Fabaceae & Domesticated & EU082123 & This study \\
\hline $\mathrm{S}$ & Naracoorte, S. Australia & $V . f a b a$ & Fabaceae & Domesticated & $\mathrm{U} 47033$ & 37 \\
\hline WHPB-1 & Wireless Hill, W. Australia & K. prostrata ${ }^{\mathrm{c}}$ & Fabaceae & Native & DQ901435 & 52 \\
\hline WHPB-2 & Wireless Hill, W. Australia & K. prostrata ${ }^{\mathrm{c}}$ & Fabaceae & Native & DQ901434 & 52 \\
\hline \multicolumn{7}{|l|}{ Non-Australian } \\
\hline $35-1$ & Saitama, Japan & Gentiana sp. & Gentianaceae & Domesticated & AB097090 & 50 \\
\hline $90-2$ & Japan & V.faba & Fabaceae & Domesticated & D89545 & 40 \\
\hline B-33 & Saitama, Japan & Gentiana sp. & Gentianaceae & Domesticated & AB097089 & 50 \\
\hline BH-8 & Hokkaido, Japan & P. vulgaris & Fabaceae & Domesticated & AB041972 & 51 \\
\hline $\mathrm{Cgz}$ & Guangzhou, China & Canna sp. & Cannaceae & Domesticated & EF592168 & Unpublished \\
\hline $\mathrm{Chz}$ & Hangzhou, China & Canna sp. & Cannaceae & Domesticated & DQ060521 & Unpublished \\
\hline $\mathrm{CS}$ & Japan & P. sativum & Fabaceae & Domesticated & AB373203 & 43 \\
\hline Csz & Shenzh, China & Canna sp. & Cannaceae & Domesticated & EF592169 & Unpublished \\
\hline Danish & Denmark & Gladiolus hybrida & Iridaceae & Domesticated & X53684 & 4 \\
\hline E-24N & Kagoshima, Japan & G. hybrida & Iridaceae & Naturalized & AB029438 & 51 \\
\hline E441 & Palampur, India & G. hybrida & Iridaceae & Domesticated & AJ844916 & Unpublished \\
\hline E-92C & Kagoshima, Japan & G. hybrida & Iridaceae & Naturalized & AB029439 & 51 \\
\hline GDD & Utah, USA & G. hybrida & Iridaceae & Domesticated & AY192568 & 18 \\
\hline Hangzhou & Hangzhou, China & Not stated & & Domesticated & AJ311371 & Unpublished \\
\hline $\mathrm{IbG}$ & Kyoto, Japan & G. hybrida & Iridaceae & Domesticated & AB079887 & 33 \\
\hline LP- $1^{d}$ & Hatay, Turkey or Homs, Syria & Lupinus pilosus & Fabaceae & Domesticated & EU082119 & 24 \\
\hline LP- $2^{d}$ & Hatay, Turkey or Homs, Syria & L. pilosus & Fabaceae & Domesticated & EU082120 & 31 \\
\hline M11 & Kyoto, Japan & G. hybrida & Iridaceae & Domesticated & AB079886 & 33 \\
\hline Masdevallia & Germany & Masdevallia sp. & Orchidaceae & Domesticated & AF185961 & Unpublished \\
\hline MB4 & Japan & G. hybrida & Iridaceae & Domesticated & D83749 & 12 \\
\hline No. 4 & Saitama, Japan & Gentiana sp. & Gentianaceae & Domesticated & AB079782 & 50 \\
\hline $\mathrm{P} 242$ & Wakayama, Japan & $P$. sativum & Fabaceae & Domesticated & AB041971 & Unpublished \\
\hline Palampur-1 & Palampur, India & G. hybrida & Iridaceae & Domesticated & AM398198 & Unpublished \\
\hline Pullman & Pullman, WA, USA & L. luteus & Fabaceae & Domesticated & EU144223 & Unpublished \\
\hline RLut- $1^{\mathrm{d}}$ & St Petersburg, Russia & L. luteus & Fabaceae & Domesticated & EU082124 & This study \\
\hline RLut- $2^{\mathrm{d}}$ & St Petersburg, Russia & L. luteus & Fabaceae & Domesticated & EU082125 & This study \\
\hline RLut- $3^{\mathrm{d}}$ & St Petersburg, Russia & L. luteus & Fabaceae & Domesticated & EU082126 & This study \\
\hline RLut- $4^{\mathrm{d}}$ & St Petersburg, Russia & L. luteus & Fabaceae & Domesticated & EU082127 & This study \\
\hline $\mathrm{S}-22 \mathrm{C}$ & Kagoshima, Japan & G. hybrida & Iridaceae & Domesticated & AB029436 & 51 \\
\hline $\mathrm{S}-22 \mathrm{~N}$ & Kagoshima, Japan & G. hybrida & Iridaceae & Domesticated & AB029435 & 51 \\
\hline Sb-12C & Kagoshima, Japan & $V \cdot f a b a$ & Fabaceae & Domesticated & AB029440 & 51 \\
\hline $\mathrm{Sb}-50 \mathrm{C}$ & Kagoshima, Japan & $V . f a b a$ & Fabaceae & Domesticated & AB029437 & 51 \\
\hline Solan & Solan, India & G. hybrida & Iridaceae & Domesticated & EF611822 & Unpublished \\
\hline Suzuki & Japan & Not stated & & $\ldots$ & $\mathrm{AB} 032023$ & Unpublished \\
\hline V124 & Kagoshima, Japan & $V \cdot f a b a$ & Fabaceae & Domesticated & AB041970 & 51 \\
\hline Verbena & USA & Verbena $\times$ hybrida & Verbenaceae & Domesticated & AY520092 & 16 \\
\hline VM-0 & India & Vanilla fragrans & Orchidaceae & Domesticated & AY845011 & Unpublished \\
\hline VM-23 & India & $V$. fragrans & Orchidaceae & Domesticated & AY845012 & Unpublished \\
\hline $\mathrm{W}$ & Idaho, USA & Lupinus albus & Fabaceae & Domesticated & DQ641248 & 19 \\
\hline ClYVV No. 30 & Hokkaido, Japan & V. faba & Fabaceae & Domesticated & AB011819 & 44 \\
\hline
\end{tabular}

a W. Australia = Western Australia; S. Australia = South Australia, Vic = Victoria, Australia; ACT = Australian Capital Territory.

${ }^{\mathrm{b}}$ Domesticated $=$ selected by man. Native $=$ wild species indigenous to the region concerned. Wild = nondomesticated species originating elsewhere but established as a wild population in the region. Naturalized = self-sustaining, uncultivated population derived from a domesticated species.

c Indigenous, undomesticated host species. In the text these native species are included in the "wild" category.

${ }^{\mathrm{d}}$ Grown from imported seed under postentry quarantine conditions, South Perth (RLut1-4) or in adjacent plots (LP-1, LP-2). 
In this paper, genetic diversity of BYMV isolates from four continents was assessed in relation to original, natural isolation hosts and the geographical locations they came from. Our aims were to (i) determine the $\mathrm{CP}$ sequences of 17 new isolates from diverse hosts and the VPg sequences of four new isolates, (ii) compare the molecular variability of these new CPs and VPgs with those of all CP and VPg sequences available on the database, and (iii) compare the phylogenetic groupings found with natural host ranges and geographical distributions of the isolates each group contained.

\section{MATERIALS AND METHODS}

Plants and virus isolates. The 19 isolates of BYMV sequenced in this study (17 $\mathrm{CP}$ and four VPg genes) came from (i) a collection of freeze-dried isolates originally obtained in 1987 to 1998 from eight species of wild (includes native and introduced wild species) or domesticated legumes from different locations in southwestern Australia (14 isolates), (ii) fresh leaves of a symptomatic $P$. vulgaris plant from Perth (southwestern Australia) obtained in 2005 (one isolate), and (iii) fresh leaves of symptomatic Lupinus luteus (yellow lupin) plants growing in 2005 in a postentry quarantine glasshouse at South Perth (four isolates). Seven CP sequences of BYMV isolates from southwestern Australia were reported earlier $(28,52,53)$, and another 40 BYMV CP sequences were available on GenBank (Table 1). A further three BYMV VPg sequences from southwestern Australia and another seven from elsewhere were also available on GenBank (Table 2). Isolate SV $(7,31)$ was renamed LP-2 here because the original SV isolate was no longer available, as it had become contaminated by isolate LP-1.

RNA extraction, reverse transcription-polymerase chain reaction (RTPCR), and sequence analyses. Total RNA from infected fresh $(100 \mathrm{mg} / \mathrm{sample})$ or freeze-dried (20 mg/sample) leaves was extracted after grinding in liquid nitrogen with an RNeasy Plant Miniprep kit (Qiagen). cDNA was synthesized using either ThermoScript reverse transcriptase (Invitrogen) or ImPromII reverse transcriptase (Promega) according to manufacturer's instructions. Random hexamer primers (Invitrogen) initiated cDNA synthesis. Amplification by polymerase chain reaction (PCR) of viral cDNA corresponding to the $\mathrm{CP}$ and VPg genes was done with Pfu DNA polymerase (Promega), which has "proofreading" ability to minimize polymerase-induced errors. Cycle conditions were as follows: one step of denaturation at $94^{\circ} \mathrm{C}$ for $5 \mathrm{~min}, 30$ cycles of $94^{\circ} \mathrm{C}$ for $10 \mathrm{~s}, 54^{\circ} \mathrm{C}$ for $30 \mathrm{~s}$, and $72^{\circ} \mathrm{C}$ for $1 \mathrm{~min}$. Amplification of the CPs was with the primers LegPotyF (5'-GCWKCH ATGATYGARGCHTGGG-3'), which anneals upstream of the $\mathrm{CP}$ within the NIb gene, and BYMVUTR-rev (5'-CTCGCT CTACAAAGATCAGGCTCACACG-3'), which anneals downstream of the $\mathrm{CP}$ within the $3^{\prime} U T R$ region. Both strands of PCR products were sequenced either (i) directly after purification with the primers used in their amplification and, where appropriate, internal $\mathrm{CP}$ primers $\mathrm{BYMV} 2$ (5'-GAGAATTTAAAGACGGATA-3'), BYMV3 (5'-GGTTTGGCCAGGTATGCT TTTG-3'), and BYMV7 (5'-GTTGTAA GGCGGTTTATTACAGCGTAAAGA-3'), or (ii) after first cloning into PCR BluntTopo (Invitrogen) vector, then using the universal primers M13F (5'-TCCCAG TCACGACGTCGT-3') and M13R (5'GGAAACAGCTATGACCATG- $3^{\prime}$ ), and internal CP primers BYMV2, BYMV3, and BYMV7. Primers used to amplify and sequence the VPg gene were BYMV13 (5'-GGGCATTGGAATAAACCAGT-3'), which anneals upstream of the VPg in the 6-kDa protein 2 gene, and BYMV14a (5'TAGGCTATGGATTCCCACTA-3'), which anneals downstream of the VPg sequence within the NIa protease gene. Either one or two clones were sequenced per isolate. Automated sequencing was done using an Applied Biosystems Industries (ABI)/ Hitachi 3730 DNA Analyzer using BigDye terminator V3.1 chemistry (ABI). Sequences were prepared by trimming off primer sequences and nontarget gene sequences and were assigned accession numbers by GenBank (Table 1).

ClustalW (47) with default parameters was employed for all alignments. CPs of isolates E593 and E715 (accession numbers AM113706 and AM113707, respectively) were excluded because these isolates apparently contained sequencing errors. Only full-length BYMV CP sequences were compared. Partial-length $\mathrm{CP}$ sequences available on the database were excluded from the analysis because they were from different "core" (conserved) or variable regions of the $\mathrm{CP}$ and so might group differently when fully sequenced. VPg gene sequences were also all fulllength. ClYVV isolate No. 30 was used as outgroup in both CP and VPg analyses.

Genetic diversity of isolates was deduced from sequence alignments in MEGA 4 (45) using four methods: neighborjoining, minimum evolution, maximum parsimony, and unweighted pair group method with arithmetic mean. Evolutionary distances were computed using the Poisson correction method for amino acids (aa) and the maximum composite likelihood model for nts. Maximum parsimony phylograms were obtained using the closeneighbor-interchange method with search level 3 in which the initial phylograms were obtained with the random addition of sequences (10 replicates). With all methods used within MEGA 4, evaluation of statistical confidence for nt and aa acid sequence groups was by the bootstrap test (1,000 replicates).

\section{RESULTS}

Coat protein gene. Sequences of 16 of the new BYMV CPs were 822 nt (274 aa) in length, but the remaining isolate (PvB1 ), along with one sequenced previously (KP), was slightly longer: $825 \mathrm{nt}$ (275 aa). When aligned with 47 other BYMV CPs from the database, maximum genetic distance between isolates was calculated by

Table 2. Isolates with genome-linked viral protein sequences used

\begin{tabular}{lllll}
\hline Isolate & Country of collection & Original host species & Family & Accession no. \\
\hline CS & Japan & Pisum sativum & Fabaceae & AB373203 \\
GDD & Utah, USA & Gladiolus hybrida & Iridaceae & AY192568 \\
IbG & Japan & G. hybrida & Iridaceae & AB079887 \\
KP & W. Australia & Kennedia prostrata & Fabaceae & EU090227 \\
LBa2-NN & W. Australia & Lupinus angustifolius & Fabaceae & AY376313 \\
LKoj1-NN & W. Australia & L. angustifolius & Fabaceae & EU090229 \\
LL7-NN & W. Australia & L. angustifolius & Fabaceae & AY373026 \\
LP-2 & W. Australia & Lupinus pilosus & Fabaceae & EU090228 \\
LutKP & W. Australia & Lupinus luteus & Fabaceae & AY376314 \\
M11 & Japan & G. hybrida & Iridaceae & AB079886 \\
MB4 & Japan & G. hybrida & Iridaceae & D83749 \\
MI & W. Australia & Melilotus indica & Fabaceae & EU090226 \\
S & S. Australia & Vicia faba & Fabaceae & U47033 \\
W & Idaho, USA & Lupinus albus & Fabaceae & DQ641248 \\
ClYVVb & Hokkaido, Japan & V. faba & Fabaceae & AB011819 \\
\hline
\end{tabular}

\footnotetext{
${ }^{\mathrm{a}} \mathrm{W}$. Australia $=$ Western Australia; S. Australia $=$ South Australia.
}

${ }^{\mathrm{b}}$ Clover yellow vein virus (ClYVV) isolate No. 30 . 
pairwise analysis to be $0.224 \mathrm{nt}$ and 0.165 aa substitutions per site. When nt and aa sequence alignments of CPs were compared by four different phylogeny methods, the phylogenetic trees formed were congruous, the 64 isolates falling into six distinct polytypic groups and one monotypic group with high bootstrap support (Fig. 1).

The most significant predictor of phylogeny of each isolate was its original, natural isolation host (Tables 1 to 3, Figs. 1 and 2), so this descriptor was used to assign the group names proposed here. The largest group contained 25 isolates obtained from eight different species in one dicotyledonous (Fabaceae) and two monocotyledonous (Iridaceae, Orchidaceae) families. Isolates within this group were originally collected in Asia, Australia, Europe, and North America from two wild and three domesticated species of legumes (Fabaceae), two wild orchid species (Orchidaceae), and the domesticated species G. hybrida (Iridaceae). It was therefore named the "general" group. The other five polytypic groups were named according to the host type from which the majority of member isolates were originally collected. All five groups comprised isolates from a single or limited number (up to four) of domesticated plant species. Ten of the 11 members of the "monocot" group were from four domesticated species, which included G. hybrida, in two monocotyledonous (Iridaceae, Orchidaceae) and one dicotyledonous (Gentianaceae) families, but the original host species of isolate Hangzhou was not listed (Table 1, Fig. 1). Isolates in this group were all from Asia and Europe. The "lupin" group consisted of seven isolates from two species of domesticated broad-leaf lupins (Fabaceae). Four isolates came from L. luteus plants grown in 2005 from seed newly imported from St Petersburg, Russia, within a postentry quarantine glasshouse facility at South Perth. Infected plants showed symptoms of leaf narrowing, distortion and mottle, and plant stunting, and were subsequently destroyed to fulfill quarantine requirements. Another two isolates (LP-1, LP-2) were obtained in 1987 from a plant of Lupinus pilosus grown from seed originally imported from Syria or Turkey and sown outside on research plots isolated within an urban area at the same research facility (25). Presence of this strain was identified again at the same site in 1998 by infection of Lupinus angustifolius genotypes that differentiate this form of BYMV from all others (8), but there is no evidence of its establishment elsewhere in Australia. The seventh isolate in the group was obtained from an L. luteus plant growing in the lupin germplasm collection maintained at Pullman, WA, USA, and presumably originated from seed transmission in this species. The "broad bean" group consisted of 12 isolates from $V$. faba plants growing in Aus-

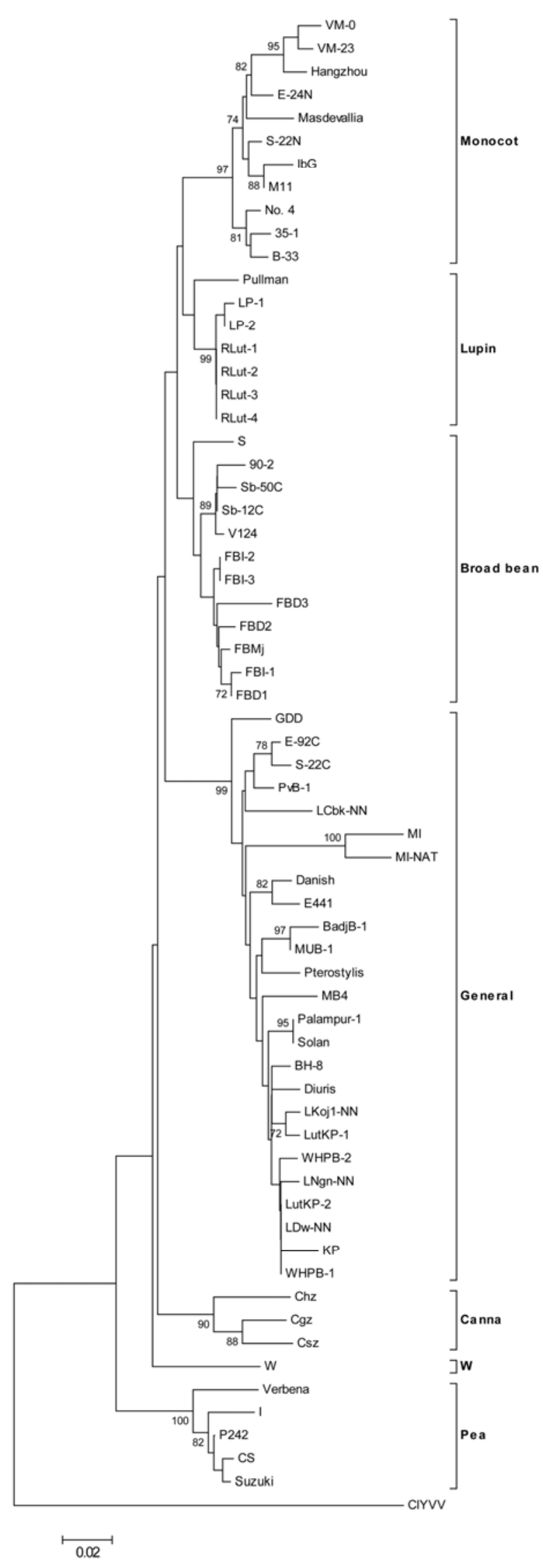

Fig. 1. Neighbor-joining relationship phylogram of the complete coat protein nucleotide sequences of 64 Bean yellow mosaic virus (BYMV) isolates, using a Clover yellow vein virus (ClYVV) isolate as the outgroup sequence. Names of the six distinct polytypic groups proposed are based on natural hosts. The phylogram is drawn to scale, with branch lengths in the same units as those of the evolutionary distances used to infer it. Phylograms were generated with MEGA 4 using default parameters. Numbers at branches indicate the percentage of 1,000 bootstrap replications where values were above $70 \%$. The evolutionary distance scale is in the units of the number of nucleotide substitutions per site. 
tralia or Asia. The "canna" group contained three isolates collected from Canna sp. (Cannaceae) in China. The "pea" group contained isolates from Asia, Australia, and North America, three originally from P. sativum (Fabaceae) and one each from Verbena $\times$ hybrida (Verbenaceae) and an unrecorded host from Japan. Isolate W from Lupinus albus (white lupin) in North America grouped apart from other isolates, so it was placed within a distinct, currently monotypic group called "W".

Within groups, overall mean nt diversity of the CP gene, as measured by substitutions per site, ranged from 0.019 (monocot) to 0.061 (general), and aa diversity ranged from 0.010 (lupin) to 0.054 (canna) (Table 4). Thus, the general group was the most genetically diverse at the nt level. Mean nt diversity between groups was from 0.112 (lupin versus monocot) to 0.219 (canna versus pea), whereas mean aa diversity ranged from 0.044 (lupin versus broad bean) to 0.138 (canna versus pea). The overall diversity (nt and aa) in the BYMV CP, as calculated by averaging all sequence pairs, was 0.153 and 0.084 , respectively. BYMV CP groups diverged from ClYVV isolate No. 30 by 0.393 to 0.421 (nt) and 0.245 to 0.277 (aa).

A highly conserved asparagine-alanineglycine (NAG) motif known to be essential for aphid transmission and located at $\mathrm{CP}$ amino acid residues 7 to 9 was maintained in all but six of the 64 isolates. There were three mutations in it: glycine to serine in isolates MI-NAT, CS, and $\mathrm{BH}-8$, glycine to aspartic acid in isolates E-92C, as reported earlier (53), and PvB-1, and alanine to valine in isolate Verbena.

VPg gene. VPg sequences of seven BYMV isolates from southwestern Australia, and seven others were $573 \mathrm{nt}$ in length (191 aa) (Table 2). Phylograms (aa, nt) with congruous branch topologies were obtained with each of the four phylogeny methods used, each resembling the consensus (Fig. 2). Phylogram branch topologies for VPgs gave five distinct groups that were sometimes incongruous with those predicted from CPs. Group I contained four G. hybrida isolates from Japan and North America that fell into monocot or general groups by $\mathrm{CP}$ analysis. Diversity within this group was low, 0.020 (nt) and 0.031 (aa) (Table 5). Group II contained three isolates collected from three legume species from southwestern Australia, two wild and one domesticated (Table 1); CP sequences placed these isolates within the general group. Diversity within this group was relatively high, 0.121 (nt) and 0.081 (aa). Group III contained five isolates, three from $L$. angustifolius, LP-2 from $L$. pilosus, and isolate $\mathrm{S}$ from $V$. faba, whereas $\mathrm{CP}$ sequences had placed one of the L. angustifolius isolates in the general group, LP-2 in the lupin group, and $\mathrm{S}$ in the broad bean group (CP sequences for the other two lupin isolates were unavailable). Genetic diversity within this group was 0.084 (nt) and 0.049 (aa). Groups IV and $\mathrm{V}$ each contained only one isolate, $\mathrm{W}$ and CS, respectively. With group IV, the $\mathrm{CP}$ of isolate $\mathrm{W}$ had placed it in monotypic group $\mathrm{W}$, while with group $\mathrm{V}$ the $\mathrm{CP}$ of isolate CS fell within the pea group. Diversity between groups was higher for $\mathrm{VPg}$ than for $\mathrm{CP}$, the nts ranging from 0.217 (I versus II) to 0.301 (IV versus V) and the aas from 0.137 (I versus III) to 0.222 (IV versus $\mathrm{V}$ ). The overall numbers of nt and aa substitutions per site within the BYMV VPg, as calculated by averaging all sequence pairs, were 0.260 and 0.073 , respectively. BYMV VPg groups diverged from the VPg of ClYVV isolate No. 30 by 0.398 to 0.497 (nt) and 0.369 to 0.424 (aa).

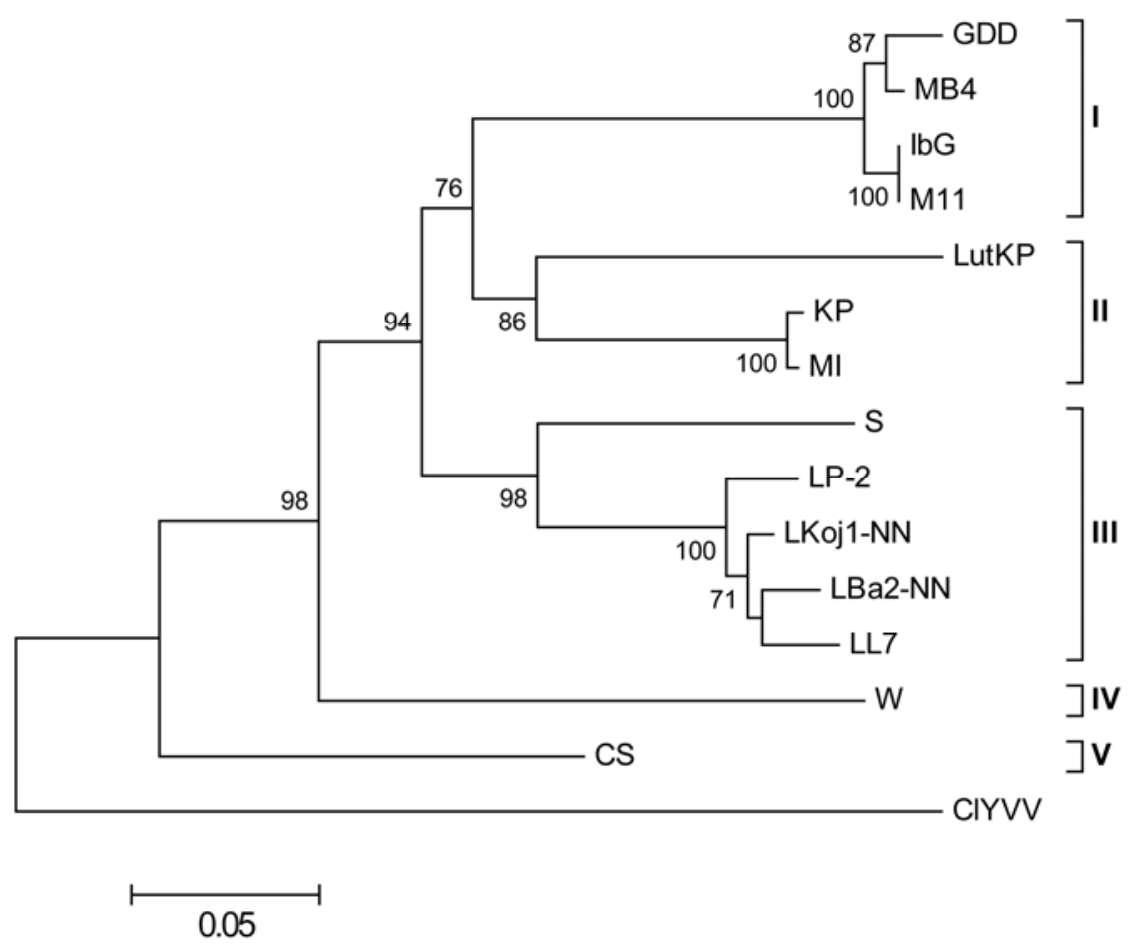

Fig. 2. Neighbor-joining relationship phylogram of the genome-linked viral protein nucleotide sequences of 14 Bean yellow mosaic virus (BYMV) isolates, using a Clover yellow vein virus (ClYVV) isolate as the outgroup sequence. The five genetically distinct groups are numbered. The phylogram is drawn to scale, with branch lengths in the same units as those of the evolutionary distances used to infer it. Numbers at the branches indicate the percentage of 1,000 bootstrap replications where values were above $70 \%$. The evolutionary distance scale is in the units of the number of nucleotide substitutions per site.

Table 3. Coat protein-derived phylogenetic groups: geographical occurrence and original natural isolation hosts

\begin{tabular}{|c|c|c|c|c|}
\hline Group name & No. isolates & Geographical origin $^{a}$ & Family $^{b}$ & Distinguishing features \\
\hline General & 25 & $\begin{array}{l}\text { Australia (16), Japan (4), India (3), } \\
\text { Denmark (1), USA (1) }\end{array}$ & $\begin{array}{l}\text { Fabaceae (15), Iridaceae (8), } \\
\text { Orchidaceae (2) }\end{array}$ & $\begin{array}{l}\text { Infects eight species of monocots and dicots, } \\
\text { domesticated and wild species }\end{array}$ \\
\hline Broad bean & 12 & Australia (8), Japan (4) & Fabaceae & Only isolates from Vicia faba \\
\hline Canna & 3 & China (3) & Cannaceae & Only isolates from Canna sp. \\
\hline Lupin & 7 & $\begin{array}{l}\text { Russia (4), Turkey or Syria (2), } \\
\text { USA (1) }\end{array}$ & Fabaceae & $\begin{array}{l}\text { Only isolates from Lupinus luteus and } \\
\text { L. pilosus }\end{array}$ \\
\hline Monocot & 11 & $\begin{array}{l}\text { Japan (7), India (2), Germany (1), } \\
\text { China (1) }\end{array}$ & $\begin{array}{l}\text { Orchidaceae (3), Iridaceae (4), } \\
\text { Gentianaceae (3), Not stated (1) }\end{array}$ & $\begin{array}{l}\text { Isolates infecting three monocotyledonous and } \\
\text { one dicotyledonous species }\end{array}$ \\
\hline Pea & 5 & Japan (3), Australia (1), USA (1) & $\begin{array}{l}\text { Fabaceae (3), Verbenaceae (1), } \\
\text { Not stated (1) }\end{array}$ & Only isolates from Pisum sativum and Verbena sp. \\
\hline W & 1 & USA & Fabaceae & Isolate from Lupinus albus \\
\hline
\end{tabular}

a Number in parentheses beside country name refers to the number of isolates from each country.

${ }^{b}$ Number in parentheses beside family name refers to the number of isolates originally from species within plant family. 


\section{DISCUSSION}

Our phylogenetic analyses were based on $\mathrm{CP}$ nt and aa sequences of 17 new BYMV isolates and another 47 from the GenBank database, representing worldwide distribution and diverse natural isolation hosts. The overall nucleotide diversity of BYMV CPs (0.224) approached the species demarcation limit of 0.23 to 0.24 substitutions per site suggested for potyviruses by Adams et al. (1). The CP nt diversity of BYMV was greater than that of 61 isolates of Zucchini yellow mosaic virus (0.206) (17) and 78 isolates of Turnip mosaic virus (0.160) (34), but smaller than that of 71 isolates of Bean common mosaic virus (0.259) (17). BYMV $\mathrm{CP}$ sequences fell into seven distinct phylogenetic groups, six polytypic and one monotypic. Six of these seven groups were defined by original natural isolation hosts. Within these host-defined groups, member isolates came from domesticated species within one to three families, and none were from wild plants. In contrast, isolates in the largest group behaved like a generalist virus with regard to natural host range $(9,48)$ because its member isolates came from wild and domesticated hosts belonging to both monocotyledons and dicotyledons. VPgbased phylogenetic groupings also tended to be defined by original, natural isolation host, but these were sometimes incongruous with CP-derived groupings. Host specialized groups probably originated where their principal hosts were first domesticated, although their phylogeography did not reveal this clearly.

The general group, which was the most diverse genetically (CP gene nt diversity of 0.061), contained BYMV isolates from monocotyledonous and dicotyledonous hosts belonging to two wild species legumes (Fa- baceae), two wild orchid species (Orchidaceae), three species of domesticated legumes, and the domesticated species $G$. hybrida (Iridaceae). Isolates within this group were from four continents. The general group corresponded to strain $\mathrm{O}(23)$, the chlorotic spot group (51) and pathotype IV (39), based on indicator host plant reactions and serology. Interpreting the maximum likelihood trees of Chare and Holmes (5) based on 24 isolates, the general group corresponded to their largest (unnamed) group. Monocot group isolates (CP gene nt diversity of 0.019), all from Eurasia, were isolated from four species of domesticated plants within two monocotyledonous (Iridaceae, Orchidaceae) and one dicotyledonous (Gentianaceae) families. The dicot host does not mean the name "monocot" needs revision because the Gentiana plants infected with three isolates may have been infected from Gladiolus plants growing nearby $(39,50,51)$, and the other eight isolates were all from monocots. All host species within this group were domesticated ornamentals whose primary means of propagation is vegetative. The monocot group corresponded to the previously named necrotic spot group (51), pathotype I (39), and another group (unnamed) of Chare and Holmes (5). International trade in infected plant propagules, such as corms of $G$. hybrida, would explain how this group moved from continent to continent (52). The broad bean group (CP gene nt diversity of 0.045 ) only contained isolates from $V$. faba, suggesting marked host adaptation $(27,42)$. Members of the broad bean group corresponded to the B strain (23) and pathotype II (39). Although the isolates within it are currently only from Japan and Australia, isolates that are readily seedborne in $V$. faba occur in Australia, Europe, and North America (e.g., 11,26), so trade in infected seed probably spread it worldwide. Interestingly, when they analyzed the first $600 \mathrm{nt}$ of the $\mathrm{CP}$ of isolate S, Chare and Holmes (5) reported it to be a divergent member of a group (unnamed) corresponding to our monocot group, but when the remaining 180 nt were used, it fell within another of their unnamed groups that corresponded with our broad bean group. These results were interpreted as evidence of genetic recombination between two groups to form isolate S. None of the previous studies revealed presence of the lupin group ( $\mathrm{CP}$ gene nt diversity of 0.032), which constitutes a distinctive domesticated broadleaf lupin-adapted clade. Isolates within the lupin group were collected from L. luteus or L. pilosus plants grown from seed from Europe, North America, and West Asia. Isolates from L. luteus from Europe and North America are seedborne in this species, as was an L. pilosus isolate from West Asia in L. pilosus (25), so the international seed trade has probably moved it widely around the world. In contrast, the lupin isolates within the general group are not seedborne in lupin, invading crops each year from self-regenerating pastures dominated by annual Trifolium spp. (clovers), where these isolates are seedborne in some clover species $(8,24,32)$. Interestingly, lupin group isolates LP-1 and LP-2 from $L$. pilosus were phenotypically distinct from lupin isolates within the general group because they induced systemic necrosis in two L. angustifolius genotypes that became infected without necrosis with isolates from L. angustifolius and clovers $(7,8)$. Isolate $\mathrm{W}$ from the domesticated broadleaf lupin species L. albus, which was distinct from all others and formed a monotypic

Table 4. Mean coat protein sequence diversity within and between the different Bean yellow mosaic virus (BYMV) groups identified by phylogenetic analysis

\begin{tabular}{|c|c|c|c|c|c|c|c|c|}
\hline Group & General & Broad bean & Canna & Lupin & Monocot & Pea & $\mathbf{W}$ & CIYVV \\
\hline General & $0.061 / 0.047^{\mathrm{a}}$ & 0.169 & 0.172 & 0.171 & 0.175 & 0.209 & 0.171 & 0.409 \\
\hline Broad bean & 0.081 & $\mathbf{0 . 0 4 5} / 0.021$ & 0.161 & 0.135 & 0.152 & 0.200 & 0.150 & 0.398 \\
\hline Canna & 0.111 & 0.086 & $\mathbf{0 . 0 4 7 / 0 . 0 5 4}$ & 0.181 & 0.190 & 0.219 & 0.162 & 0.404 \\
\hline Lupin & 0.076 & 0.044 & 0.080 & $\mathbf{0 . 0 3 2} / 0.010$ & 0.112 & 0.214 & 0.157 & 0.393 \\
\hline Monocot & 0.099 & 0.072 & 0.110 & 0.063 & $\mathbf{0 . 0 1 9} / 0.034$ & 0.217 & 0.168 & 0.421 \\
\hline Pea & 0.120 & 0.107 & 0.138 & 0.104 & 0.127 & $\mathbf{0 . 0 3 0} / 0.027$ & 0.191 & 0.396 \\
\hline $\mathrm{W}$ & 0.106 & 0.068 & 0.101 & 0.064 & 0.105 & 0.110 & $\ldots$ & 0.414 \\
\hline ClYVV & 0.277 & 0.245 & 0.249 & 0.242 & 0.267 & 0.250 & 0.257 & $\ldots$ \\
\hline
\end{tabular}

a Number of base substitutions per site calculated by pairwise analysis. Intergroup mean sequence diversity is indicated above (nucleotides) and below (amino acids) the diagonal. Intragroup mean sequence diversity is indicated on the diagonal for nucleotides (in bold) and amino acids (italics). Clover yellow vein virus (ClYVV) isolate No. 30 used as outgroup.

Table 5. Mean genome-linked viral protein sequence diversity within and between the different Bean yellow mosaic virus (BYMV) groups identified by phylogenetic analysis

\begin{tabular}{|c|c|c|c|c|c|c|}
\hline Group & I & II & III & IV & $\mathbf{V}$ & CIYVV \\
\hline I & $\mathbf{0 . 0 2 0} / 0.031^{\mathrm{a}}$ & 0.217 & 0.235 & 0.318 & 0.287 & 0.497 \\
\hline II & 0.140 & $\mathbf{0 . 1 2 1} / 0.081$ & 0.219 & 0.282 & 0.297 & 0.474 \\
\hline III & 0.137 & 0.145 & $\mathbf{0 . 0 8 4} / 0.049$ & 0.277 & 0.295 & 0.455 \\
\hline IV & 0.219 & 0.211 & 0.188 & & 0.301 & 0.473 \\
\hline V & 0.196 & 0.205 & 0.205 & 0.222 & & 0.398 \\
\hline CIYVV & 0.412 & 0.411 & 0.376 & 0.424 & 0.369 & $\ldots$ \\
\hline
\end{tabular}

${ }^{a}$ Number of base substitutions per site calculated by pairwise analysis. Intergroup mean sequence diversity is indicated above (nucleotides) and below (amino acids) the diagonal. Intragroup mean sequence diversity is indicated on the diagonal for nucleotides (in bold) and amino acids (italics). Clover yellow vein virus (ClYVV) isolate No. 30 used as outgroup. 
group, was originally from the United States. Pea group isolates (CP gene nt diversity of 0.030 ) were from three continents: Australia, Asia, and North America. Three sequenced isolates were from $P$. sativum and one apparently was from the non-leguminous ornamental Verbena $\times$ hybrida (Verbenaceae). This group corresponded to the P strain of BYMV (23), pathotype III (39), and an unnamed group (5). BYMV isolates that are seedborne in $P$. sativum occur worldwide (e.g., 11), so like broad bean and lupin group isolates, this group was probably spread widely through the international seed trade. Isolates of BYMV from Canna sp. (probably C. edulis, arrowroot) collected in China formed another distinct grouping not described previously (CP gene nt diversity of 0.047). Although BYMV isolates from Canna spp. are recorded from several other countries (29), sequence data from them are lacking. It is not known if BYMV is seedborne in Canna spp. but they are usually propagated from rhizome cuttings, so this group probably moved internationally when these were traded.

Like the CP-based groups, those formed by phylogenetic analysis of the $14 \mathrm{VPg}$ sequences of BYMV were strongly correlated with original natural isolation host, but branch topologies of phylograms were sometimes incongruous between genes. Group I consisted solely of G. hybridaderived isolates, suggesting genetic adaptation to this host. However, CP analysis of these isolates divided them into the general and monocot groups, suggesting that their CPs evolved differently from their VPgs or genetic recombination had occurred. Group II placed three CP-derived general group isolates together, but Group III mixed isolates from broad bean, lupin, and general CP-derived groups, again suggesting that the $\mathrm{CP}$ and the VPg evolved separately. Intragroup diversity was generally higher for VPgs than for CPs (0.020 to 0.121 [nt] and 0.031 to 0.081 [aa] versus 0.019 to 0.061 [nt] and 0.010 to 0.054 [aa]), respectively. Across all 14 isolates, the VPg was more genetically diverse than the CP gene $(0.260$ versus 0.153 , respectively). This indicates that the $\mathrm{CP}$ is more conserved, presumably because it is involved in host determination both directly and indirectly $(10,22,38)$.

A possible scenario for the existence of the CP-based BYMV groups that occur today is that an ancestral population, represented here by the general group, coevolved within wild plant communities containing genetically diverse host species. When humans domesticated plants and grew such plants intensively, variants within this ancestral BYMV population evolved to specialize in infecting certain domesticated plant species, represented by the five specialist groups. BYMV, therefore, may have evolved such that, during the last ten or so millennia (27), the gen- eral group split into distinct components that adjusted to the domestication of different types of plants for agriculture within isolated plant domestication centers. However, the ancestral general group also remained, retaining its ability to infect a diverse range of monocotyledonous and dicotyledonous hosts, both wild and domesticated. Occurrence of different BYMV groups, one using a generalist strategy and the others specializing in different types of domesticated plants, may help explain its widespread presence in ecosystems and agroecosystems worldwide.

The center of origin of the general group of BYMV was presumably somewhere in Eurasia. However, although this might be expected to be the region that holds its maximum genetic diversity (20,27,42, 48,52), this was not apparent from the phylogeographic data. Thus, although isolates from four groups (monocot, broad bean, pea, and general) were all found in Japan, none of the domesticated plant hosts involved (Gentiana sp., G. hybrida, $P$. sativum, or $V . f a b a$ ) were originally domesticated from wild ancestors there. Instead, the considerable scientific interest in characterizing BYMV in Japan (31\% of $\mathrm{CP}$ sequences) explains its apparent diversity in that country. Similarly, members of three distinct groups (pea, broad bean, and general) occur in Australia (39\% of CP sequences), but apart from four isolates from wild plants, all were obtained from domesticated plants introduced in the last two centuries following European colonization. Isolates sequenced from Australian indigenous plants (the orchids Pterostylis curta and Diuris maculata and the legume Kennedia prostrata) seem to be recent invaders and closely resemble general group isolates from elsewhere. Thus, BYMV diversity in Australia is better explained by recent multiple incursions of the virus from overseas. Narrow diversity of the CPs of isolates previously described in Australia (52) highlights the need to characterize sequences from as wide a range of natural hosts as possible before making conclusions regarding genetic diversity.

Centers of domestication of $L$. albus, $L$. angustifolius, L. luteus, L. pilosus, P. sativum, and $V . f a b a$ are all in Eurasia, while Canna sp. was domesticated in Central/South America $(20,21,48)$. Domesticated G. hybrida and Freesia spp. (Iridaceae), natural host species of BYMV, originate from southern Africa (35), but no BYMV isolates from there have been sequenced as yet. Possibly G. hybrida is a recent opportunistic host, not an ancient one. Thus, the monocot group might have coevolved with domesticated Iris or Crocus (Iridaceae) host species, the ancestors of which are indigenous to Eurasia, and are now widely grown as ornamental plants worldwide. Whether the canna group originated in the Americas within its principal host or infected Canna sp. after it arrived in China remains unresolved. Monotypic Group W, represented by a single isolate from the United States, seems sufficiently distinct to indicate that it may have arisen after a long period of isolation.

\section{ACKNOWLEDGMENTS}

We thank Yvonne Cheng for collecting some of the BYMV isolates used, Belinda Welsh and Craig Webster for help with sequencing some isolates, Nancy Robertson, USDA, for early access to the sequence of isolate Pullman, and the Australian Quarantine Inspection Authority for access to postentry quarantine facilities at South Perth. The Western Australian Department of Agriculture and Food and Murdoch University provided financial support.

\section{LITERATURE CITED}

1. Adams, M. J., Antoniw, J. F., and Fauquet, C. M. 2005. Molecular criteria for genus and species discrimination within the family Potyviridae. Arch. Virol. 150:459-479.

2. Barnett, O. W., Randles, J. W., and Burrows, P. M. 1987. Relationships among Australian and North American isolates of the bean yellow mosaic potyvirus subgroup. Phytopathology 77:791-799.

3. Beauchemin, C., Boutet, N., and Laliberte, J.F. 2007. Visualization of the interaction between the precursors of the VPg, the viral protein linked to the genome of Turnip mosaic virus, and the translation initiation factor iso $4 \mathrm{E}$ in planta. J. Virol. 81:775-782.

4. Boye, K., Jensen, P. E., Stummann, B. M., and Henningsen, K. W. 1990. Nucleotide sequence of cDNA encoding the BYMV coat protein gene. Nucleic Acids Res. 18:4926.

5. Chare, E. R., and Holmes, E. C. 2006. A phylogenetic survey of recombination frequency in plant RNA viruses. Arch. Virol. 151:933-946.

6. Cheng, Y., and Jones, R. A. C. 1999. Distribution and incidence of necrotic and non-necrotic strains of bean yellow mosaic virus in wild and crop lupins. Aust. J. Agric. Res. 50:589-599.

7. Cheng, Y., and Jones, R. A. C. 2000. Biological properties of necrotic and non-necrotic strains of bean yellow mosaic virus in cool season grain legumes. Ann. Appl. Biol. 136:215-227

8. Cheng, Y., Jones, R. A. C., and Thackray, D. J. 2002. Deploying strain specific hypersensitive resistance to diminish temporal virus spread. Ann. Appl. Biol. 140:69-79.

9. Cooper, J. I., and Jones, R. A. C. 2006. Wild plants and viruses: Under-investigated ecosystems. Adv. Virus Res. 67:1-47.

10. Dolja, V. V., Haldeman, R., Robertson, N. L. Dougherty, W. G., and Carrington, J. C. 1994 Distinct functions of capsid protein in assembly and movement of tobacco etch potyvirus in plants. EMBO J. 13:1482-1491.

11. Edwardson, J. R., and Christie, R. G. 1991 CRC Handbook of Viruses Infecting Legumes. CRC Press, Boca Raton, FL.

12. Fujisawa, I., Mikoshiba, Y., and Nakalima, T. 1991. The prevalent virus diseases on main crops in Tohoku district. Misc. Publ. Tohoku National Agricultural Experiment Station 11:111 (in Japanese).

13. Gao, Z., Johansen, E., Eyers, S., Thomas, C. L., Noel-Ellis, T. H., and Maule, A. J. 2004 The potyvirus recessive gene, $s b m 1$, identifies a novel role for translation initiation factor eIF4E in cell-to-cell trafficking. Plant J. 40:376-385

14. Gibbs, A., Mackenzie, A., Blanchfield, A., Cross, P., Wilson, C., Kitajima, E., Nightingale, M., and Clements, M. 2000. Viruses of 
orchids in Australia: Their identification, biology and control. Aust. Orchid Rev. 65:10-21.

15. Gillaspie, A. G., Jr., Hopkins, M. S., Pinnow, D. L., and Jordan, R. L. 1998. Characteristics of a potyvirus of the bean yellow mosaic virus subgroup in Sesbania speciosa germ plasm. Plant Dis. 82:807-810.

16. Guaragna, M. A., Jordan, R. L., and Putnam, M. L. 2004. First report of Bean yellow mosaic virus (pea mosaic strain) in Verbena $\times$ hybrida. Plant Dis. 88:574.

17. Ha, C., Revill, R. M., Harding, R. M., Vu, M., and Dale, J. L. 2008. Identification and sequence analysis of potyviruses infecting crops in Vietnam. Arch. Virol. 153:45-60.

18. Hammond, J., and Hammond, R. W. 1989. Molecular cloning, sequencing and expression in Escherichia coli of the bean yellow mosaic virus coat protein gene. J. Gen. Virol. 70:19611974.

19. Hampton, R. O., Shukla, D. D., and Jordan, R. L. 1992. Comparative potyvirus host range, serology, and coat protein peptide profiles of white lupin mosaic virus. Phytopathology 82:566-571.

20. Harlan, J. R. 1971. Agricultural origins: Centers and noncenters. Science 174:468-474.

21. Heinz, B. 2006. The isthmus of Panama as a crossroad for prehistoric migration of domesticated plants. Geojournal 14:121-122.

22. Hofius, D., Maier, A. T., Dietrich, C., Jungkunz, I., Börnke, F., Maiss, E., and Sonnewald, U. 2007. Capsid protein-mediated recruitment of host DnaJ-like proteins is required for $\mathrm{Po}$ tato virus $Y$ infection in tobacco plants. J. Virol. 81:11870-11880.

23. Inouye, T. 1968. Studies on host range of PVY-group viruses in leguminous plants in Japan, and the identification of them by selected differential test plants. Nogaku Kenkyu 52:1129 (in Japanese).

24. Jones, R. A. C. 1992. Further studies on losses in productivity caused by infection of annual pasture legumes with three viruses. Aust. J. Agric. Res. 43:1229-1241.

25. Jones, R. A. C., and McLean, G. D. 1989. Virus diseases of lupins. Ann. Appl. Biol. 114:609-637.

26. Latham, L. J., and Jones, R. A. C. 2001. Incidence of virus infection in experimental plots, commercial plots and seed stocks of cool season crop legumes. Aust. J. Agric. Res. 52:397413.

27. Lovisolo, O., Hull, R., and Rosler, O. 2003. Coevolution of viruses with hosts and vectors and possible palaeontology. Adv. Virus Res. 62:325-379.

28. Mathews, A., Dwyer, G., Wylie, S. J., and Jones, M. G. K. 1995. Nucleotide and deduced amino acid sequence of the $3^{\prime}$ end of the BYMV-MI genome. Arch. Virol. 140:22692272.

29. Monger, W. A., Harju, V., Skelton, A., Seal, S. E., and Mumford, R. A. 2007. Canna yellow streak virus: A new potyvirus associated with severe streaking symptoms in canna. Arch. Virol. $152: 1527-1530$

30. McKern, N. M., Barnett, O. W., Whittaker, L. A., Mishra, A., Strike, P. M., Xiao, X. W. Ward, C. W., and Shukla, D. D. 1993. Sequence relationships among the coat proteins of strains of pea mosaic, white lupin mosaic, and bean yellow mosaic potyviruses. Phytopathology 83:355-361.

31. McKirdy, S. J., Coutts, B. A., and Jones, R. A. C. 1994. Occurrence of bean yellow mosaic virus in subterranean clover pastures and perennial native legumes. Aust. J. Agric. Res. 45:183-194.

32. McKirdy, S. J., and Jones, R. A. C. 1995. Bean yellow mosaic potyvirus infection of alternative hosts associated with subterranean clover (Trifolium subterraneum) and narrow-leafed lupins (Lupinus angustifolius): Field screening procedure, relative susceptibility/resistance rankings, seed transmission and persistence between growing seasons. Aust. J. Agric. Res. 46:135-152.

33. Nakazono-Nagaoka, E., Satoh, G., Kosaka, Y., and Natsuaki, T. 2004. Evaluation of crossprotection with an attenuated isolate of Bean yellow mosaic virus by differential detection of virus isolates using RT-PCR. J. Gen. Plant Pathol. 70:359-362.

34. Ohshima, K., Yamaguchi, Y., Hirota, R., Hamamoto, T., Tomimura, K., Tan, Z., Sano, T., Azuhata, F., Walsh, J. A., Fletcher, J., Chen, J., Gera, A., and Gibbs, A. 2002. Molecular evolution of Turnip mosaic virus: Evidence of host adaptation, genetic recombination and geographical spread. J. Gen. Virol. 83:15111521

35. Pressey, R. L., Cowling, R. M., and Rouget, M. 2003. Formulating conservation targets for biodiversity pattern and process in the Cape Floristic Region, South Africa. Biol. Cons. 112:99-127.

36. Rajamäki, M.-L., and Valkonen, J. P. T. 1999. The $6 \mathrm{~K} 2$ protein and the VPg of Potato virus A are determinants of systemic infection in $\mathrm{Ni}$ candra physaloides. Mol. Plant-Microb. Interact. 12:1074-1081

37. Randles, J. W., Davies, C., Gibbs, A. J., and Hatta, T. 1980. Amino acid composition of capsid protein as a taxonomic criterion for classifying the atypical S strain of bean yellow mosaic virus. Aust. J. Biol. Sci. 33:245-254

38. Rojas, M. R., Zerbini, F. M., Allison, R. F., Gilbertson, R. L., and Lucas, W. J. 1997. Capsid protein and helper component-proteinase function as potyvirus cell-to-cell movement proteins. Virology 237:283-295.

39. Sasaya, T., Nozu, Y., and Koganezawa, H. 1998. Biological and serological comparisons of bean yellow mosaic virus (BYMV) isolates in Japan. Ann. Phytopathol. Soc. Jpn. 64:24-33.

40. Sasaya, T., Shimizu, T., Nozu, Y., Nishiguchi, M., Inouye, N., and Koganezawa, H. 1997. Biological, serological, and molecular variabilities of clover yellow vein virus. Phytopa- thology 87:1014-1019.

41. Shukla, D. D., Ward, W. W., and Brunt, A. A. 1994. The Potyviridae. Wallingford, CAB International, UK.

42. Spetz, C., Taboada, A. M., Darwich, S., Ramsell, J., Salazar, L. F., and Valkonen, J. P. T. 2003. Molecular resolution of a complex of potyviruses infecting solanaceous crops at the centre of origin in Peru. J. Gen. Virol $84: 2565-2578$

43. Takahashi, T., Uyeda, I., Ohshima, K., and Shikata, E. 1990. Nucleotide sequence of the capsid protein gene of bean yellow mosaic virus chlorotic spot strain. J. Fac. Agric. Hokkaido University 64:152-163.

44. Takahashi, Y., Takahashi, T., and Uyeda, I. 1997. A cDNA clone to clover yellow vein poyvirus genome is highly infectious. Virus Genes 14:235-243.

45. Tamura, K., Dudley, J., Nei, M., and Kumar, S. 2007. MEGA4: Molecular Evolutionary Genetics Analysis (MEGA) software version 4.0 Mol. Biol. Evol. 24:1596-1599.

46. Taylor, R. H., and Smith, P. R. 1968. The relationship between bean yellow mosaic virus and pea mosaic virus. Aust. J. Biol. Sci. 21:429-437.

47. Thompson, J. D., Higgins, D. G., and Gibson, T. J. 1994. CLUSTAL W: Improving the sensitivity of progressive multiple sequence alignment through sequence weighting, positionspecific gap penalties and weight matrix choice. Nucleic Acids Res. 22:4673-4680.

48. Thresh, J. M., ed. 1981. Pests, Pathogens and Vegetation. Pitman, London, UK.

49. Tracy, S. L., Frenkel, M. J., Gough, K. H., Hanna, P. J., and Shukla, D. D. 1992. Bean yellow mosaic, clover yellow vein, and pea mosaic are distinct potyviruses: Evidence from coat protein gene sequences and molecular hybridization involving the $3^{\prime}$ non-coding regions. Arch. Virol. 122:249-261.

50. Uga, H., Kobayashi, Y. O., Hagiwara, K., Honda, Y., and Omura, T. 2004. Selection of an attenuated isolate of Bean yellow mosaic virus for protection of dwarf gentian plants from viral infection in the field. J. Gen. Plant Pathol. 70:54-60

51. Wada, Y., Iwai, H., Ogawa, Y., and Arai, K. 2000. Comparison of pathogenicity and nucleotide sequences of $3^{\prime}$-terminal regions of bean yellow mosaic virus isolates from Gladiolus. J. Gen. Plant Pathol. 66:345-352.

52. Webster, C. G., Coutts, B. A., Jones, R. A. C., Jones, M. G. K., and Wylie, S. J. 2007. Virus impact at the interface of an ancient ecosystem and a recent agroecosystem: Studies on three legume-infecting potyviruses in the southwest Australian floristic region. Plant Pathol. 56:729-742.

53. Wylie, S. J., Kueh, J., Welsh, B., Smith, L. J., Jones, M. G. K., and Jones, R. A. C. 2002. A non aphid-transmissible isolate of bean yellow mosaic potyvirus has an altered NAG motif in its coat protein. Arch. Virol. 147:1813-1820.

\section{ERRATUM}

This article was changed on 4 December 2008 to reflect the fact that Gentiana sp. was incorrectly stated to be a monocot, when it is actually a dicot. Gentiana sp. was infected with monocot group Bean yellow mosaic virus (BYMV) isolates. Also, the general group of BYMV isolates was stated to have been found in three domesticated species when the actual number was four. 